\title{
Contribution of the novel sulfur-producing adjunct Lactobacillus nodensis to flavor development in Gouda cheese
}

\author{
Elaine O’Brien, ${ }^{*} \dagger$ Susan Mills, $† \ddagger$ Alleson Dobson, ${ }^{*} \dagger$ L. Mariela Serrano, $†$ John Hannon, ${ }^{*}$ Siobhan P. Ryan, ${ }^{*}$ \\ Kieran N. Kilcawley, ${ }^{*}$ Johannes B. Brandsma, $†$ Wilco C. Meijer, $†$ Colin Hill, $\neq \S$ and R. Paul Ross $\#^{1}$ \\ ${ }^{*}$ Teagasc Food Research Centre, Moorepark, Fermoy, Co. Cork, Ireland \\ †CSK Food Enrichment, Ede 6718 ZC, the Netherlands \\ ¥APC Microbiome Institute, \\ $\S$ School of Microbiology, and \\ \#College of Science, Engineering and Food Science, University College Cork, Cork, Ireland
}

\begin{abstract}
We assessed the efficacy of Lactobacillus nodensis CSK964 as an adjunct culture in Gouda cheese under various industrial conditions. We set up 4 different systems: a direct vat inoculum with and without adjunct using the calf rennet Kalase, and an undefined bulk starter culture with and without adjunct using the microbial rennet Milase (both rennets from CSK Food Enrichment, Ede, the Netherlands). During ripening, we subjected the cheeses to the following analyses: viability of starter and adjunct cells, composition, proteolysis, and flavor development by detection of sulfur compounds and descriptive sensory analysis. In general, the presence of $L b$. nodensis increased secondary proteolysis and influenced cheese flavor, particularly in relation to volatile sulfur compounds; hydrogen sulfide and methanethiol were present in higher abundances in cheeses containing $L b$. nodensis. The primary starter also influenced the range of volatile sulfur compounds produced. Methanethiol and dimethyl disulfide were more abundant in the nisin-producing direct vat inoculum cheese with adjunct; hydrogen sulfide was more prevalent when bulk starter culture was used with $L b$. nodensis. Sensory analysis revealed that the direct vat inoculum cheese with adjunct scored significantly better in terms of smell and taste than the direct vat inoculum cheese without adjunct and lacked the dominant sulfur flavors of the bulk starter cheese with adjunct. Subsequent analysis using lead acetate paper and modified motility broth as indicators of hydrogen sulfide production confirmed that $L b$. nodensis produced hydrogen sulfide in broth and in the cheese matrix. This study suggests that the inclusion of $L b$. nodensis as an adjunct culture can significantly alter the flavor profile of the fi-
\end{abstract}

Received July 11, 2016.

Accepted January 23, 2017.

${ }^{1}$ Corresponding author: p.ross@ucc.ie nal cheese. However, the selection of a suitable primary starter is imperative to ensure a desirable product. Key words: Lactobacillus nodensis, Gouda cheese, adjunct, volatile sulfur compounds

\section{INTRODUCTION}

Flavor development during cheese ripening is the result of a series of biochemical processes, the 3 primary being glycolysis (lactose and citrate metabolism), proteolysis (casein degradation), and lipolysis (fat metabolism; Marilley and Casey, 2004; McSweeney, 2004; van den Berg et al., 2004). Along with the coagulant used and the indigenous milk enzymes, the starter bacteria (mainly lactic acid bacteria; LAB) and their enzymes play a significant role as either primary or secondary starters (Singh et al., 2003).

Primary starter cultures, including lactococci and streptococci, are required for the consistent development of acidity during cheesemaking by converting lactose to lactic acid, and they play an important role in the biological protection of the product. Secondary starters or adjuncts, on the other hand, play an essential role in ripening, leading to flavor development mainly through proteolysis (Settanni and Moschetti, 2010; Gobbetti et al., 2015). These cultures, more often referred to as nonstarter LAB (NSLAB), normally comprise mesophilic lactobacilli or highly lytic lactococci. They increase the rate of casein hydrolysis, resulting in high levels of small peptides and free amino acids - precursors for many flavor and aroma compounds.

Proteolysis is considered the most complex and important primary biochemical change with regard to texture and flavor formation (Smit et al., 2005). Following the action of the coagulant (primary proteolysis) and the LAB cell-envelope proteinase and peptidases, small peptides and free amino acids are transported into the cell via dedicated transport systems (Savijoki et al., 2006). Intracellular peptidases further degrade 
the small peptides to free amino acids (secondary proteolysis), which are then available for conversion into various flavor compounds, including acids, esters, alcohols, aldehydes, and sulfur-containing compounds (Smit et al., 2005).

The breakdown of sulfur-containing amino acids methionine and cysteine is regarded as a particularly important process, leading to the development of specific dairy flavors (van Kranenburg et al., 2002; Lee et al., 2007) resulting from methanethiol, dimethyl disulfide, dimethyl trisulfide, hydrogen sulfide $\left(\mathrm{H}_{2} \mathrm{~S}\right)$ and dimethyl sulfide (Liu et al., 2008). However, sulfur compounds may also negatively affect the final flavor of the product, depending on the particular compound and its relative abundance (Landaud et al., 2008). Because methionine and cysteine are present in low concentrations in milk, the development of sulfur aromas in cheese depends greatly on the biosynthesis and presence of catabolic pathways for methionine and cysteine in the starter bacteria. Consequently, we need to understand the sulfur-producing capabilities of cheese cultures to use them effectively in cheese production.

The species Lactobacillus nodensis was recognized in 2009 following the isolation of gram-positive, rodshaped, non-motile LAB from Japanese pickles (Kashiwagi et al., 2009). It was later isolated from Danish raw milk cheeses in a study identifying metabolically active bacteria during the ripening process (Masoud et al., 2011). The genome sequence of $L b$. nodensis CSK964, from the CSK Food Enrichment (Ede, the Netherlands) culture collection, has recently been made available (Dobson et al., 2014). Preliminary analysis revealed the presence of 3 genes required for conversion of glycine to cysteine: glyA (serine hydroxymethyltransferase), cysE (serine acetyltransferase), and cysK (cysteine synthase; van Kranenburg et al., 2002). Although the full complement of genes required for methionine synthesis was not observed, 2 methionine aminopeptidases were identified on the genome that release $\mathrm{N}$-terminal methionine from polypeptide chains (Hirel et al., 1989). Hydrogen sulfide can be generated from cysteine or homocysteine via the activity of cysteine synthase or cystathionine lyases (Liu et al., 2008). As well as cysteine synthase, a gene with homology to cystathionine-gamma-lyase was iden- tified on the genome sequence of $L b$. nodensis CSK964, suggesting that this strain can produce volatile sulfur compounds including $\mathrm{H}_{2} \mathrm{~S}$ (Dobson et al., 2014).

In the present study, we assessed the effectiveness of the strain $L b$. nodensis CSK964 as an adjunct in Gouda cheese using 2 different systems, which included combination with a nisin-producing direct vat inoculum starter (DVI) in the presence of calf rennet or a bulk starter culture (BSC) in the presence of microbial rennet. We evaluated the viability of the adjunct in the cheeses, cheese composition, flavor development based on assessment of proteolysis, presence of sulfur compounds, and sensory qualities. We confirmed the ability of $L b$. nodensis CSK964 to influence flavor formation in Gouda cheese, with a notable contribution to "sulfur" flavors. The strain was subsequently shown to produce $\mathrm{H}_{2} \mathrm{~S}$ using modified motility sulfide broth (MMSB) in the presence of lead acetate paper (Lee and Simard, 1984). Moreover, the importance of selecting suitable combinations of starter, adjunct, and coagulant became apparent, because changes in any of these parameters influenced the final product.

\section{MATERIALS AND METHODS}

\section{Cheese Manufacture}

In the present study, 4 separate Gouda cheeses were manufactured on an industrial scale (see Table 1 for details). The DVI culture was composed of 3 CSK strains: Lactococcus lactis ssp. cremoris CSK0083 (185.5 g/1,500 L), Lc. lactis ssp. lactis biovar diacetylactis CSK0062 (185.5 g/1,500 L), and Lactobacillus helveticus CSK0090 (200 g/1,500 L). The DVI (from frozen pellet, $10^{10} \mathrm{cfu} / \mathrm{g}$ ) was added directly to cheese milk at an inoculation rate of $375 \mathrm{~g} / 1,500 \mathrm{~L}$ at $30^{\circ} \mathrm{C}$. The natural calf rennet Ceska-lase Kalase [150 international milk clotting units/mL; CSK Food Enrichment, Ede, the Netherlands] was used in the manufacture of the DVI-prepared Gouda cheese.

For BSC-prepared Gouda cheese, $2.5 \mathrm{~mL}$ of a CSK complex mesophilic bulk starter (from frozen pellet, $\left.10^{10} \mathrm{cfu} / \mathrm{g}\right)$ was inoculated into high pasteurized milk $\left(102^{\circ} \mathrm{C}, 30 \mathrm{~min}\right)$ and incubated for $18 \mathrm{~h}$ at $20^{\circ} \mathrm{C}$, after

Table 1. Overview of Gouda cheese samples used in this study

\begin{tabular}{lll}
\hline $\begin{array}{l}\text { Sample } \\
\text { code }\end{array}$ & Starter culture system & Rennet used $^{1}$ \\
\hline Vat 1 & Direct vat inoculum only & Ceska-lase Kalase \\
Vat 2 & Direct vat inoculum + Lactobacillus nodensis CSK964 & Ceska-lase Kalase \\
Vat 3 & Bulk starter culture only & Milase \\
Vat 4 & Bulk starter culture + Lactobacillus nodensis CSK964 & Milase \\
\hline
\end{tabular}

${ }^{1}$ Rennets from CSK Food Enrichment (Ede, the Netherlands). 
which $0.4 \%$ (wt/wt) of the freshly prepared bulk starter was used to inoculate the cheese milk. The microbial rennet Milase (750 international milk clotting units/ $\mathrm{mL}$; CSK Food Enrichment) was used in Gouda cheeses prepared with the BSC. For adjunct-containing cheeses, $32.5 \mathrm{~g}$ of $\mathrm{Lb}$. nodensis/1,500 L of cheese milk was used.

Gouda cheeses were manufactured by CSK Food Enrichment at the pilot plant of Nizo Food Research (Ede, the Netherlands), as previously described by Mills et al. (2011). Milk was bactofugated at $68^{\circ} \mathrm{C}$ for $13 \mathrm{~s}$ and pasteurized at $73^{\circ} \mathrm{C}$ for $13 \mathrm{~s}$, and then the cheese milk was cooled to $32^{\circ} \mathrm{C}$. Starter/adjunct was added to each vat to result in bacterial counts of $10^{6}-10^{8} / \mathrm{g}$ in fresh, unripened cheese (24-h cheeses). The different rennet types were added, and after a coagulation time of approximately $35 \mathrm{~min}$, the curd was cut and the whey drained. Following this, the curd was washed, pressed, salted (24-h-old cheeses) and ripened for up to $140 \mathrm{~d}$ at $13^{\circ} \mathrm{C}$. Each cheese was manufactured from 1,500 L of milk, resulting in 15 cheese wheels per vat. Each wheel weighed approximately $12 \mathrm{~kg}$ and had a diameter of approximately $35 \mathrm{~cm}$ and height of approximately $10 \mathrm{~cm}$.

\section{Microbiological Analysis}

For both microbiological and compositional analysis, the rind of each cheese was removed and the remainder of the sample was used. The growth of starter LAB, NSLAB, and $L b$. nodensis was determined as follows. Samples (1 g) were homogenized as 10-fold dilutions in maximum recovery diluent (Oxoid Ltd., Basingstoke, UK). Homogenized samples were serially diluted, and $1 \mathrm{~mL}$ of each dilution was pour-plated in selective media. Starter LAB were enumerated on M17 agar (Difco Laboratories, Detroit, MI) supplemented with 0.5\% (wt/vol) lactose, and incubated aerobically for $3 \mathrm{~d}$ at $30^{\circ} \mathrm{C}$. The NSLAB were enumerated on Lactobacillus selective agar (LBS; BD Diagnostic Systems, Heidelberg, Germany) and incubated anaerobically for $5 \mathrm{~d}$ at $30^{\circ} \mathrm{C}$. Because $L b$. nodensis is intrinsically resistant to the glycomacropeptide vancomycin, it was enumerated on LBS supplemented with $250 \mu \mathrm{g} / \mathrm{mL}$ vancomycin (Sigma Aldrich Ltd., Arklow, Ireland) and incubated anaerobically for $5 \mathrm{~d}$ at $30^{\circ} \mathrm{C}$. Microbiological analysis was performed on duplicate samples from each cheese wheel at each time point.

\section{Lb. nodensis CSK964 Viability in the Presence of Nisin}

The viability of $L b$. nodensis CSK964 in the presence of nisin was investigated as follows. A series of $10 \%$ reconstituted skim milk samples were set up with concentrations of nisin (Sigma Aldrich Ltd.) ranging from
0 to 300 activity units $(\mathbf{A U}) / \mathrm{mL}$ (the final concentration of nisin in Gouda cheese was approximately 300 $\mathrm{AU} / \mathrm{g}$; concentrations over $300 \mathrm{AU} / \mathrm{mL}$ could lead to the death of the culture). A $1 \%$ inoculum (vol/vol) of Lb. nodensis CSK964 was inoculated into each sample. Each tube was incubated at $30^{\circ} \mathrm{C}$ for $24 \mathrm{~h}$. Every $2 \mathrm{~h}$ for $12 \mathrm{~h}, 1-\mathrm{mL}$ samples were removed, diluted 1:10 in maximum recovery diluent, and plated onto MRS (De Man, Rogosa, Sharpe, 1960; Difco Laboratories) with $250 \mu \mathrm{g} / \mathrm{mL}$ of vancomycin. At $24 \mathrm{~h}$, samples were also plated on MRS-vancomycin agar. Plates were incubated aerobically at $30^{\circ} \mathrm{C}$. All experiments were performed in triplicate.

\section{Compositional Analysis}

Compositional analysis was performed on Gouda cheese samples collected during ripening on d 42 and 91. The $\mathrm{pH}$ was measured by mixing $20 \mathrm{~g}$ of a grated sample of cheese with $12 \mathrm{~mL}$ of distilled water and recording the $\mathrm{pH}$ with a Microprocessor $\mathrm{pH}$ meter (Hanna Instruments Ltd., Bedfordshire, UK). Moisture content was measured by oven-drying $3 \mathrm{~g}$ of cheese to a constant weight at $102^{\circ} \mathrm{C}$ (IDF, 1982), and salt content was measured using the potentiometric method (Fox, 1963). Grated cheese $(2 \mathrm{~g})$ and distilled water $(60 \mathrm{~mL})$ were homogenized for $10 \mathrm{~s}$, after which $4 N$ nitric acid solution was added $(3 \mathrm{~mL})$. The contents were titrated with silver nitrate using a potentiometer, type PHM 92 (Radiometer, Copenhagen, Denmark) provided with a reference electrode and a measuring electrode suitable for determining chloride levels. Compositional analysis was performed on duplicate samples from each cheese wheel at each time point.

\section{Assessment of Proteolysis}

Proteolysis was assessed by determining the levels of $\mathrm{N}$ soluble in water at $\mathrm{pH} 4.6(\mathbf{p H} \mathbf{4 . 6 - N})$ using the method of Kuchroo and Fox (1982), where N was determined by the Kjeldahl method (IDF, 1986) and results were expressed as a percentage of total N. The levels of phosphotungstic acid-soluble N (PTA-N) (5\% wt/ wt) were measured according to the method of Reiter et al. (1969), where $\mathrm{N}$ was determined by the Kjeldahl method (IDF, 1986) and results were expressed as a percentage of total $\mathrm{N}$. Cheese samples were taken at d 42 and 91 during ripening: $60 \mathrm{~g}$ of grated sample was mixed with $120 \mathrm{~mL}$ of distilled water at $50^{\circ} \mathrm{C}$ and blended for $5 \mathrm{~min}$. The resulting homogenate was incubated at $55^{\circ} \mathrm{C}$ for $1 \mathrm{~h}$. The homogenate was centrifuged $(2,500 \times g)$ for $20 \mathrm{~min}$ at $4^{\circ} \mathrm{C}$, after which it was filtered through glass wool to remove the fat. The resulting water-soluble extract was adjusted to $\mathrm{pH} 4.6$ using 2.7 
$M \mathrm{HCl}$ and centrifuged at $3,000 \times g$ for $20 \mathrm{~min}$ at $4^{\circ} \mathrm{C}$. Finally, the filtrate was passed through glass wool to produce the $\mathrm{pH}$ 4.6-soluble extract. The levels of $\mathrm{pH}$ 4.6- $\mathrm{N}$ were determined by the Kjeldahl method (IDF, 1986).

Levels of PTA-N were determined from a $20-\mathrm{mL}$ sample of $\mathrm{pH}$ 4.6-soluble extract: $12 \mathrm{~mL}$ of $9.2 \mathrm{~N} \mathrm{H}_{2} \mathrm{SO}_{4}$, $6 \mathrm{~mL}$ of $33.3 \%$ dodeca-tungstophosphoric acid (commonly known as phosphotungstic acid; BHD, VWR International Ltd., Poole, UK), and $2 \mathrm{~mL}$ of distilled water were then added. Samples were filtered the following day using a Whatman 42 ashless filter paper. Once filtered, $10-\mathrm{mL}$ samples were removed to determine PTA-N by the Kjeldahl method (IDF, 1986). Analysis was performed on duplicate samples from each cheese wheel at each time point.

Free amino acids in the $\mathrm{pH} 4.6-\mathrm{N}$ extract were measured as follows. Deproteinization was performed by mixing equal volumes of $24 \%$ (wt/vol) trichloroacetic acid and the sample; these were allowed to stand for $10 \mathrm{~min}$ before centrifuging at $14,400 \times g$ for $10 \mathrm{~min}$ (Micro Centaur; MSE, London, UK). Supernatants were removed and diluted with $0.2 \mathrm{M}$ sodium citrate buffer, $\mathrm{pH} 2.2$, to give approximately $250 \mathrm{nmol}$ of each amino acid residue. Samples were then diluted 1 in 2 with the internal standard norleucine to give a final concentration of $125 \mathrm{nmol} / \mathrm{mL}$. Amino acids were quantified using a Jeol JLC-500/V amino acid analyzer [Jeol (UK) Ltd., Garden City, UK) fitted with a Jeol $\mathrm{Na}^{+}$ high-performance cation exchange column; $20 \mu \mathrm{L}$ of each sample was injected onto the column, and amino acids separated and eluted from the column using a $\mathrm{pH}$ gradient generated using sodium citrate buffers. Amino acids were then quantified by post-column ninhydrin derivatization using colorimetric detection. Analysis was performed on 1 sample from each cheese wheel at each time point.

\section{Solid-Phase Microextraction Chromatography}

The method of Burbank and Qian (2008) was used to detect volatile sulfur compounds with modifications. Volatile sulfur compounds in the Gouda cheeses were extracted with a 1-cm Stableflex CAR-PDMS fiber (Supelco, Bellefonte, PA). Before use, the fiber was conditioned at $300^{\circ} \mathrm{C}$ for 60 min. A CombiPAL solidphase microextraction autosampler (CTC analytics AG, Zwingen, Switzerland) and a Varian CP-3800 gas chromatograph (Java Analytical Ltd., Dublin, Ireland), equipped with a pulse flamed photometric detector (PFPD), were used. Samples were aseptically taken from an internal part of fresh cheese and grated with a plastic grater. Then, $1 \mathrm{~g}$ of the grated cheese sample was added at a refrigerated temperature to a $20 \mathrm{~mL}$ glass amber headspace vial with a magnetic screw cap (Apex Scientific, Maynooth, Co. Kildare, Ireland) with a silicone/polytetrafluoroethylene septum. The samples were pre-equilibrated at $50^{\circ} \mathrm{C}$ for 10 min with agitation at $500 \mathrm{rpm}$. The fiber was exposed to the headspace at $50^{\circ} \mathrm{C}$ for $30 \mathrm{~min}$ with agitation at $250 \mathrm{rpm}$. A blank was run between each injection to check that no carryover occurred between samples. A standard consisting of dimethyl disulfide, dimethyl trisulfide, dimethyl sulfone, and dimethyl sulfoxide in methanol was run at the start and end of every sample run to monitor the performance of the solid-phase microextraction fiber.

The volatile compounds extracted by the solid-phase microextraction fiber were thermally desorbed at $300^{\circ} \mathrm{C}$ in the GC injector in splitless mode for 4 min. After 4 min, split was introduced at $270^{\circ} \mathrm{C}$ for 10 min to clean the fiber. Separation of the analytes was achieved using a DB-FFAP fused silica capillary column $(30 \mathrm{~m} \times 0.32$ $\mathrm{mm}, 1.0 \mu \mathrm{m}$; SGE Analytics, Ringwood, Australia) with a constant helium flow rate of $2.0 \mathrm{~mL} / \mathrm{min}$. The oven temperature program was as follows: $35^{\circ} \mathrm{C}$ held for $5 \mathrm{~min}$, heated to $150^{\circ} \mathrm{C}$ at a rate of $10^{\circ} \mathrm{C} / \mathrm{min}$, held for $1 \mathrm{~min}$, then heated to $220^{\circ} \mathrm{C}$ at a rate of $20^{\circ} \mathrm{C} / \mathrm{min}$ with a final hold time of $5 \mathrm{~min}$. The PFPD was held at $300^{\circ} \mathrm{C}$ and $450 \mathrm{~V}$ with the hydrogen flow rate at 14 $\mathrm{mL} / \mathrm{min}$, air 1 flow rate at $17 \mathrm{~mL} / \mathrm{min}$, and air 2 flow rate at $10 \mathrm{~mL} / \mathrm{min}$. The detector response signals were collected and integrated using computer software (Star Workstation 6.2; Agilent Technologies, Santa Clara, CA). Analysis was performed on duplicate samples from each cheese wheel at each time point.

\section{Sensory Analysis}

Sensory analysis was performed on 42-d ripened Gouda cheeses. All cheese samples were analyzed for texture and flavor attributes by an expert panel called Essensor (Essensor B.V., Ede, the Netherlands). The sensory panel consisted of 8 professionally qualified sensory graders trained according to the ISO standard 8586; each panelist possessed at least 1 certificate on sensorial evaluation. The descriptive sensory analysis of the cheese was performed using the descriptors outlined in Figure 2, which were used to determine the overall texture and flavor of the cheese. Samples were transported to Essensor as fresh 12-kg cheese blocks at the end of the selected ripening period. Samples were stored overnight at 6 to $10^{\circ} \mathrm{C}$ and then allowed to reach room temperature before evaluation. A 20-g sample was removed from the middle of the cheese block. Panelists evaluated cheeses individually in separate sensory booths. Sensory attributes were scored using an algorithm that incorporated consistency, smell/ taste, and cut, from 3 (very bad) to 8 (very good). 
Other attributes were scored from 0 (none) to 4 (very strong). Cheeses scored under 3 were described as being devoid of attributes. The sensory data were recorded using a professional sensory data acquisition and calculation analysis program called FIZZ (http://www. biosystemes.com/sensory-analysis.php).

\section{Analysis of $\mathrm{H}_{2} \mathrm{~S}$ Production}

Production of the volatile compound $\mathrm{H}_{2} \mathrm{~S}$ was assessed using lead acetate paper suspended in the headspace of a tube containing MMSB (Lee and Simard, 1984). The MMSB was inoculated with the bacterium $(2 \%)$ under investigation, and the tube containing lead acetate paper was incubated at $30^{\circ} \mathrm{C}$ overnight under aerobic conditions, after which the paper was examined for visible signs of blackening, which is indicative of $\mathrm{H}_{2} \mathrm{~S}$ production.

The concentration of $L b$. nodensis required to blacken the lead acetate paper was determined by preparing serial dilutions of the fresh overnight culture in MMSB with lead acetate paper suspended in the headspace of each tube. The dilutions were simultaneously plated on MRS agar. The MRS agar plates were incubated at $30^{\circ} \mathrm{C}$ overnight under aerobic conditions.

The ability of $L b$. nodensis to produce $\mathrm{H}_{2} \mathrm{~S}$ in cheese was assessed by adding $1 \mathrm{~g}$ of each cheese to $5 \mathrm{~mL}$ of MMSB with lead acetate paper as described above and incubating the samples at $30^{\circ} \mathrm{C}$ overnight under aerobic conditions. A negative control was also set up without the addition of the cheese. All experiments were performed in triplicate.

To determine whether $\mathrm{H}_{2} \mathrm{~S}$ production was strainspecific, 7 Lactobacillus strains previously grown in MRS (Lb. nodensis, Lb. casei DPC6125, Lb. acidophilus DPC5378, Lb. delbrueckii ssp. delbrueckii DPC5385, Lb. delbrueckii ssp. lactis DPC5387, Lb. delbrueckii ssp. bulgaricus DPC5383, and Lb. helveticus DPC4571) were assessed for their ability to produce $\mathrm{H}_{2} \mathrm{~S}$ as described above.

\section{Statistical Analysis}

Two sample $t$-tests were performed using the data analysis tool in Excel 2016 (Microsoft, Redmond, WA), where statistical significance was accepted at $P<0.05$. Initially, the DVI and BSC cheeses were compared with each other on the respective days (42 or 91) as follows: vat 1 (DVI) with vat 3 (BSC); vat $2(\mathrm{DVI}+L b$. nodensis) with vat 4 (BSC + Lb. nodensis) for parameters tested (compositional analysis, microbiological analysis, pH4.6-N, PTA-N). Comparisons within the DVI cheeses were performed using the 2 -sample $t$-test, where vat 1 was compared with vat 2 for parameters tested on the respective days. Likewise, vats 3 and 4 (BSC cheeses) were compared on the respective days using the 2 -sample $t$-test.

\section{RESULTS AND DISCUSSION}

\section{Microbiological Analysis}

The viability of the starter LAB (both DVI and BSC) and NSLAB (primarily the adjunct $L b$. nodensis) in the manufactured Gouda cheeses was investigated over the ripening period (d 42 and 91; Table 2). In terms of starter LAB, we did not observe significant differences in population numbers between the BSC and DVI-manufactured cheeses. In the DVI-manufactured cheeses, we did observe minor reductions in starter LAB, irrespective of the addition of $L b$. nodensis CSK964 (vat 1 and 2), but this was not statistically significant. We detected starter LAB at $6.5 \times 10^{6} \mathrm{cfu} / \mathrm{g}$ in the DVIonly cheese (vat 1 ) by d 42 and at $1 \times 10^{6} \mathrm{cfu} / \mathrm{g}$ by d 91. We observed an approximate $1.5-\log$ reduction in starter LAB viability throughout the ripening period in Gouda cheese containing the adjunct $L b$. nodensis CSK964 (vat 2). We detected starter LAB cell viability for BSC-manufactured cheese (vat 3) at $8.5 \times 10^{5} \mathrm{cfu} / \mathrm{g}$ by d 42 and at $1.5 \times 10^{6} \mathrm{cfu} / \mathrm{g}$ by d 91 . We observed a 1.3-log increase in starter LAB in BSC-manufactured cheese containing the adjunct $L b$. nodensis over the ripening period (vat 4) but this finding was not statistically significant.

We compared NSLAB viability for vat $2(\mathrm{DVI}+L b$. nodensis) and vat $4(\mathrm{BSC}+L b$. nodensis) on $\mathrm{d} 42$ and 91. Mean populations of $L b$. nodensis CSK964 (selected on LBS with vancomycin) in DVI-manufactured cheese (vat 2) were at $2.5 \times 10^{3} \mathrm{cfu} / \mathrm{g}$ of cheese after $42 \mathrm{~d}$ of ripening, significantly different from $L b$. nodensis numbers in BSC-manufactured cheese (vat 4) at the same time point $\left(5.5 \times 10^{7} \mathrm{cfu} / \mathrm{g} ; P=0.001\right)$. After 91 $\mathrm{d}$ of ripening, $L b$. nodensis could not be detected in the DVI-manufactured cheese (vat 2) but was recorded at $2.5 \times 10^{7} \mathrm{cfu} / \mathrm{g}$ in the BSC-manufactured cheese (vat 4; $P=0.008$ ) at the same time point. We recorded NSLAB enumerated on LBS medium at similar numbers.

Because the DVI culture produces nisin, we evaluated the viability of the adjunct strain under various concentrations of the bacteriocin (data not shown) in $10 \%$ reconstituted skim milk. In the presence of $80 \mathrm{AU} /$ $\mathrm{mL}$ of nisin, the viability of the strain dropped $4 \mathrm{log}$ $\mathrm{cfu} / \mathrm{mL}$, and at a concentration of $100 \mathrm{AU} / \mathrm{mL}$, the growth of the strain was inhibited. We concluded that the nisin produced by the DVI inhibited adjunct proliferation during the ripening period. 


\section{Compositional Analysis}

The compositional analyses of Gouda cheeses manufactured with a DVI or BSC in the presence or absence of the adjunct culture $L b$. nodensis following 42 and 91 $\mathrm{d}$ of ripening are outlined in Table 3 . We observed no significant differences for moisture, $\mathrm{pH}$, or salt between vat 1 (DVI) and vat 2 (DVI $+L b$. nodensis) at 42 or $91 \mathrm{~d}$ of ripening. Likewise, we observed no significant differences for $\mathrm{pH}$, moisture, or salt across the BSC cheeses (vats 3 and 4 ). When we compared the DVI cheeses with the BSC cheeses, the moisture content of vat 1 (DVI) at d $91(36.8 \%)$ was significantly different from the moisture content of vat 3 (BSC) at the same time point $(40.0 \% ; P<0.01)$. Salt levels were significantly different between vat 1 (DVI; $2.1 \%$ ) and vat 3 (BSC; $1.6 \%)$ on d $42(P<0.01)$. Salt levels were also significantly different between vat 2 and vat 4 on d 42 and $91(P<0.05$ and $P<0.01$, respectively $)$, where levels were higher for Gouda cheese manufactured with the DVI. This may be attributed to the fact that more salt was incorporated into the cheese during its manufacture compared with Gouda cheese made with the BSC (vats 3 and 4). The composition of Gouda cheese recorded in this study reflected the compositional analysis of Gouda cheese from previous studies (Stadhouders and Hup, 1975; Welthagen and Viljoen, 1998; Wang et al., 2011).

\section{Assessment of Proteolysis}

The level of soluble $\mathrm{N}$ at $\mathrm{pH} 4.6(\mathrm{pH} 4.6-\mathrm{N})$ is an indicator of primary proteolysis, whereas PTA-N is an indicator of low molecular weight peptides and free amino acids (secondary proteolysis; Bansal et al., 2010). Overall, the levels of proteolysis in each of the DVI and BSC cheeses increased over time, with highest levels in the adjunct-containing cheeses.

For primary proteolysis, we initially compared the DVI cheeses with the BSC cheeses (Figure 1A). We observed significant differences between vat 1 (DVI) and vat $3(\mathrm{BSC})$ at $\mathrm{d} 42(P<0.05)$ and $91(P<0.01)$. Vat 2 (DVI $+L b$. nodensis) and vat $4(\mathrm{BSC}+L b$. nodensis) were also significantly different at d $42(P$ $<0.01)$ and $91(P<0.05)$. Rennet is responsible for primary proteolysis (Sheehan, 2007). In this respect, the differences observed were presumably the result of using 2 different types of rennet coagulants: Kalase, a calf rennet (DVI-manufactured cheeses), and Milase, a microbial rennet (BSC-manufactured cheeses). We observed the highest rate of proteolysis in the cheese manufactured with commercial calf rennet. This was in contrast with studies that reported higher levels of protein hydrolysis when microbial rennet was used 


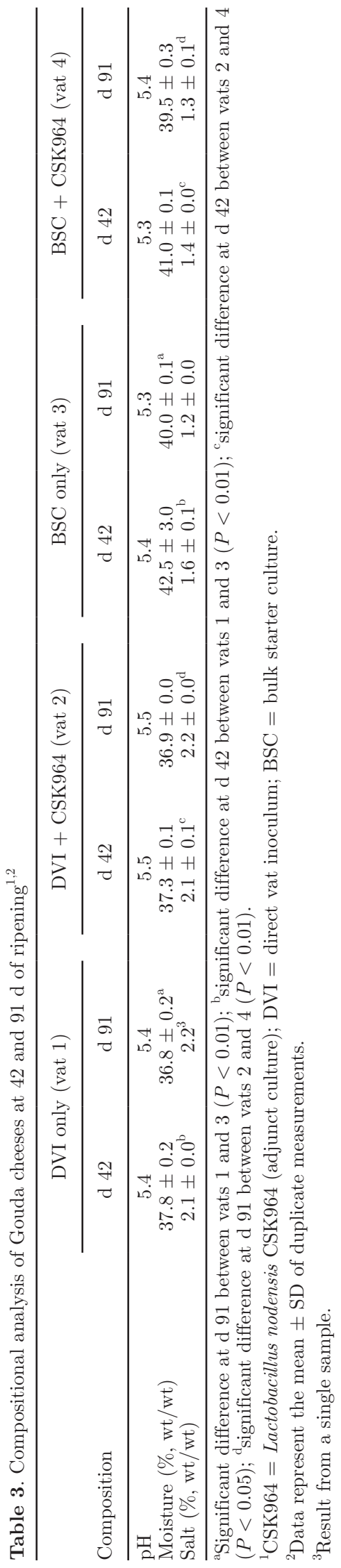

(Jacob et al., 2010, 2011; An et al., 2014). However, other studies have reported no statistically significant differences between cheeses manufactured with calf rennet and microbial rennet in terms of parameters tested, including total $\mathrm{N}$ and water-soluble $\mathrm{N}$ (Garcia et al., 2012; Ufuk and Tulay, 2012; Mehmet and Bedia, 2015). The DVI cheeses contained a proteolytic Lb. helveticus strain, but CSK0090 is known to influence secondary proteolysis only. When comparing the DVI cheeses in terms of primary proteolysis, vats 1 and 2 were significantly different at d $42(P<0.05)$, but not at d 91 . When we compared the BSC cheeses, vats 3 and 4 were significantly different at d $91(P<0.01)$, but not at $\mathrm{d}$ 42.

For secondary proteolysis (Figure 1B) vats 2 (DVI $+L B$. nodensis $)$ and $4(\mathrm{BSC}+L b$. nodensis $)$ were significantly different at $\mathrm{d} 42(P<0.001)$ and $91(P<$ $0.001)$, where PTA-N levels were much higher in the DVI cheeses. This was presumably due to a combination of a nisin-producing operon and the autolytic nature of the DVI used, because these characteristics are commonly associated with a greater concentration of free amino acids (Chapot-Chartier et al., 1994; Wilkinson et al., 1994a,b; Benech et al., 2003; Hannon et al., 2003). Indeed, nisin, whether encapsulated or produced by a strain, induces lysis of the starter culture, leading to the release of intracellular enzymes. Lb. helveticus CSK0090 may also influence secondary proteolysis. However, we observed no significant differences between vats 1 (DVI) and 3 (BSC).

When we compared the DVI cheeses, we observed significant differences between vats 1 (DVI) and 2 (DVI + Lb. nodensis) at d $91(P<0.01)$. Indeed, PTA-N levels were $0.65 \%$ total $\mathrm{N}$ for vat 2 compared with $0.15 \%$ total $\mathrm{N}$ for vat 1 . When we compared the BSC cheeses, PTA$\mathrm{N}$ levels for vats 3 (BSC) and 4 (BSC + Lb. nodensis) were significantly different at d $42(P<0.001)$ and 91 $(P<0.05)$. At d 42, PTA-N levels were $0.1 \%$ for vat 3 and $0.18 \%$ for vat 4 . At d 91 , levels were $0.17 \%$ for vat 3 and $0.3 \%$ for vat 4 . Similar to our observation that the presence of $L b$. nodensis increases PTA-N levels, Wang et al. (2011) noted that Gouda cheese manufactured with the adjunct $L b$. helveticus ND01 led to a higher concentration of PTA-N compared with the control; however, the values they observed were much higher than those we observed.

In general, the presence of $L b$. nodensis CSK964 resulted in higher levels of free amino acids, regardless of the starter system used (Figure 1C, Table 4), where levels were highest in the DVI-manufactured cheese containing Lb. nodensis. Although the DVI in this case inhibited the growth of $L b$. nodensis based on microbiological analysis, it is feasible that a percentage of the $L b$. nodensis population was in a dormant 
non-culturable state, not having fully lysed over the ripening period. Cells in such a state may still be metabolically active (Martín-Platero et al., 2008) and continue to play a role during the ripening period. In addition, previous studies have shown that the use of
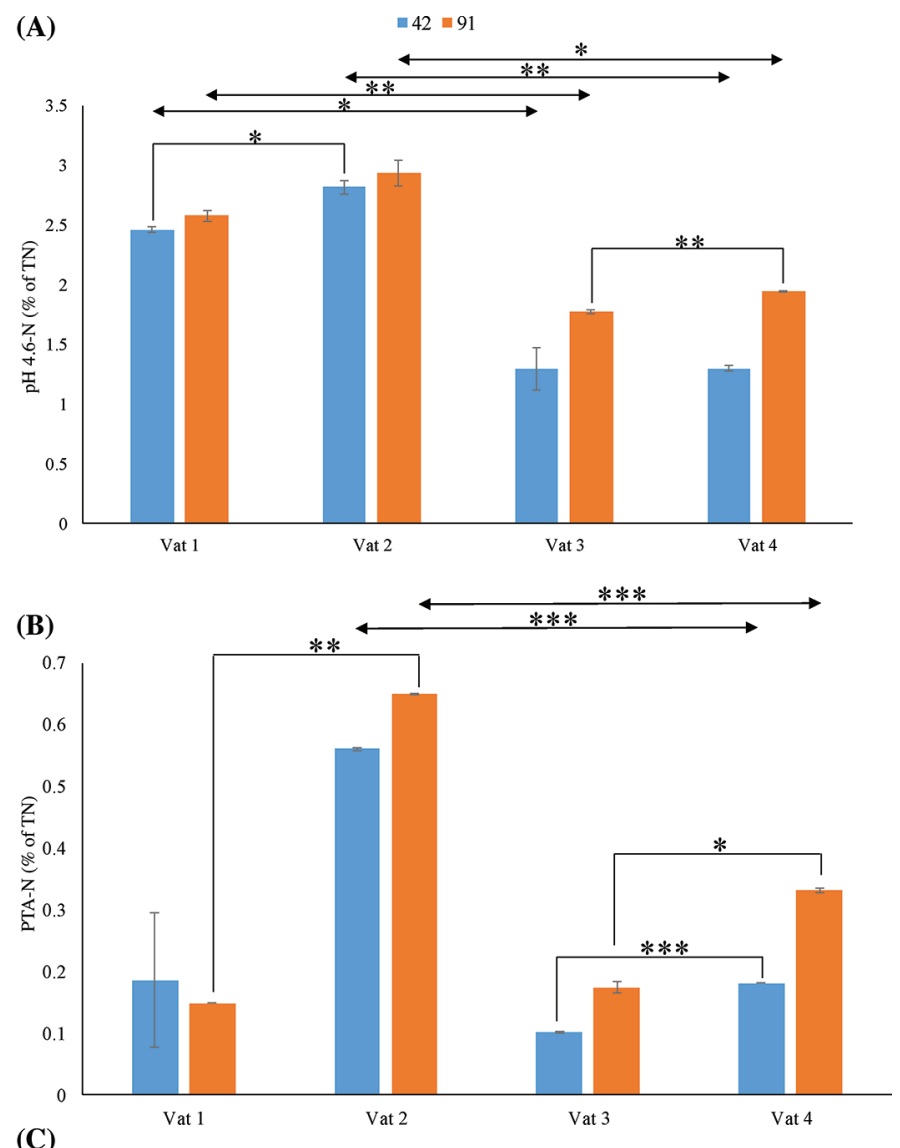

(C)

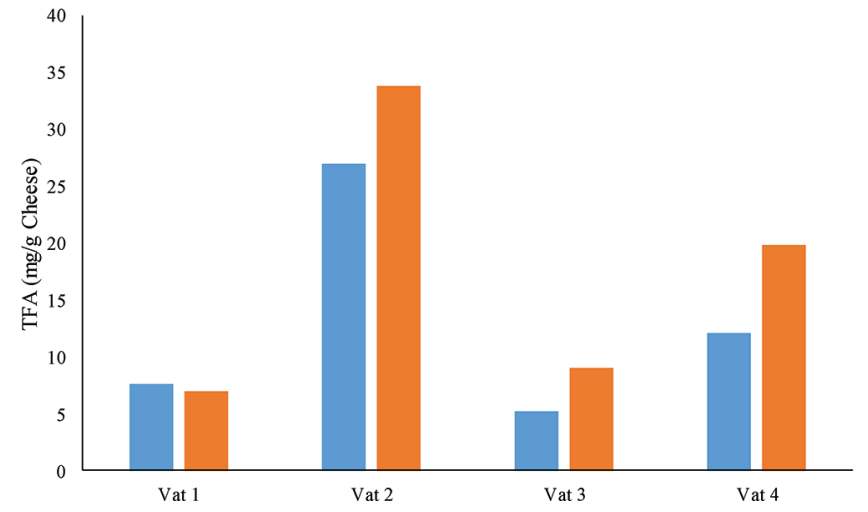

Figure 1. (A) Average values for $\mathrm{pH}$ 4.6-soluble nitrogen (pH4.6$\mathrm{N})$ and (B) phosphotungstic acid-soluble nitrogen (PTA-N) expressed as \% of total $\mathrm{N}$ (\% of TN) for cheeses at d 42 and 91 of ripening; (C) total free AA (TFA) concentrations in Gouda cheese following 42 and $91 \mathrm{~d}$ of ripening $\left({ }^{*} P<0.05 ;{ }^{* *} P<0.01 ;{ }^{* * *} P<0.001\right)$. Vat $1=$ direct vat inoculum; vat $2=$ direct vat inoculum + Lactobacillus nodensis CSK964; vat $3=$ bulk starter culture; vat $4=$ bulk starter culture + Lb. nodensis CSK964. Error bars represent SD. Color version available online. nisin-producing strains has led to a significant increase in free amino acids (de Ruyter et al., 1997; Sallami et al., 2004). In the present study, 4 principal free amino acids were dominant (glutamate, leucine, lysine, and proline) in samples containing $L b$. nodensis (Table 4). Most notably, levels of glutamate were elevated for DVI cheese containing $L b$. nodensis, reaching 6.0 and 7.4 $\mathrm{mg} / \mathrm{g}$ at 42 and $91 \mathrm{~d}$ of ripening, respectively, but only 2.0 and $1.5 \mathrm{mg} / \mathrm{g}$ at the same time points in the control cheese. Levels of glutamate were also elevated in the BSC cheese made with $L b$. nodensis ( 2.4 and $4.2 \mathrm{mg} / \mathrm{g}$ at 42 and $91 \mathrm{~d}$, respectively) compared with the control cheese (1.2 and $2.2 \mathrm{mg} / \mathrm{g}$ at 42 and $91 \mathrm{~d}$, respectively).

Levels of cysteine were relatively similar in the cheese containing the adjunct strain, regardless of the starter culture system employed.

\section{Detection and Identification of Sulfur- Containing Compounds}

Volatile sulfur compounds result mainly from the catabolism of methionine and cysteine by the cheese microbiota and contribute greatly to the final aroma of dairy products.

We detected the occurrence of sulfur compounds in the Gouda cheeses manufactured using 2 distinct starter systems using gas chromatography with a specific sulfur detector (PFPD), where results represented the peak area in arbitrary units $(\times 1,000)$ and a greater peak area reflected a higher concentration of the compound in question (Table 5). Regardless of the choice of starter culture, Gouda cheese manufactured with the adjunct $L b$. nodensis produced a minimum of 6 sulfur-containing compounds, including $\mathrm{H}_{2} \mathrm{~S}$; however, we observed differences in volatile profiles, with variation occurring between each batch of cheese. Two particular sulfur compounds - namely carbon disulfide and dimethyl sulfide - were present in high concentrations in all cheeses, regardless of adjunct presence. The volatile sulfur compound $\mathrm{H}_{2} \mathrm{~S}$ was present in higher abundances in Gouda cheese containing Lb. nodensis (vats 2 and 4) compared with the control cheeses (vats 1 and 3). In particular, we detected elevated levels of $\mathrm{H}_{2} \mathrm{~S}$ in BSC Gouda cheese with added adjunct (vat 4), and levels of methanethiol were higher for DVI Gouda cheese containing the adjunct (vat 2). The reduction in $\mathrm{H}_{2} \mathrm{~S}$ levels in DVI-manufactured cheese containing $L b$. nodensis may have been linked to the loss of cell viability in the adjunct with the nisin-producing starter.

\section{Sensory Analysis}

We performed a descriptive sensory analysis on d 42 ripened Gouda cheese manufactured with either BSC 
O'BRIEN ET AL.

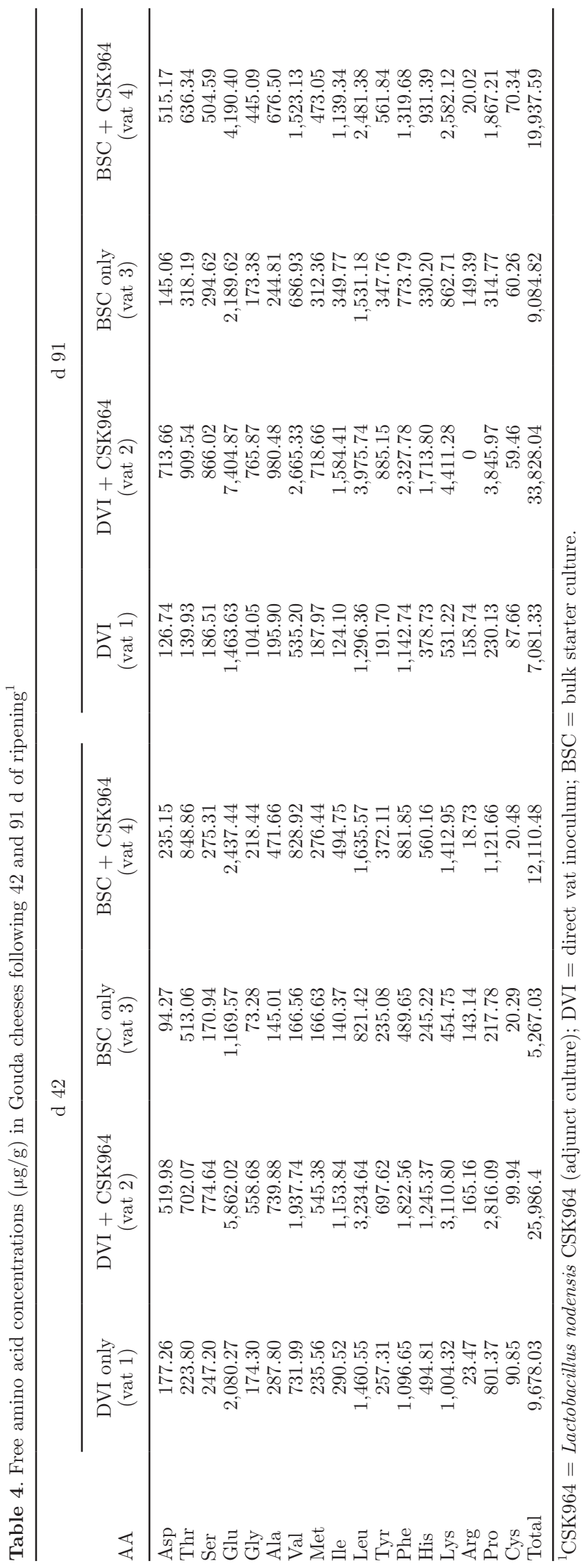


or DVI, with and without $L b$. nodensis. The analysis was performed using 8 descriptive terms to determine the overall texture and flavor of the cheese. The sensory attributes are illustrated in Figure 2. We observed significant differences in scores between the control and experimental cheeses. The DVI cheese containing $L b$. nodensis was described as "sweet" $(P<0.0001)$, lacking the bitterness attributed to the control cheese without the adjunct $(P<0.0001)$. Interestingly, cheeses manufactured with microbial rennets, as in the case of the BSC cheese, have been reported to exhibit higher levels of bitterness due to the breakdown of casein by bitter peptide-producing bacteria (Jacob et al., 2010, 2011). However, we did not observe this, because the DVI cheese (without adjunct) produced with calf rennet scored highest for bitterness. The overall textural character of the DVI cheese containing $L b$. nodensis was similar to the control cheese (Figure 2). We noted few differences in texture, but the flavor profile of the BSC cheese with Lb. nodensis CSK964 was significantly different than that of the control cheese (Figure 2). The combination of the BSC with Lb. nodensis (vat 4) caused an imbalance of flavors, leading to a dominant sulfur-flavored cheese and unpleasant odors (rotten eggs; $P<0.0001$ ). The control cheese (vat 3 ) containing BSC only lacked the "sharp hydrogen sulfide gas" smell noted in the adjunct-containing cheese.

The sensory results indicated that the DVI cheese containing $L b$. nodensis (vat 2 ) had the best overall texture and flavor compared with the other experimental cheeses.

\section{Analysis of $\mathrm{H}_{2} \mathrm{~S}$ Production}

Because analysis of volatile sulfur compounds in the cheeses indicated that $L b$. nodensis CSK964 could produce $\mathrm{H}_{2} \mathrm{~S}$, we assessed its ability to produce the gas in the presence of lead acetate paper in MMSB (Figure 3 ). This test detects trace levels of $\mathrm{H}_{2} \mathrm{~S}$ gas, resulting in the production of lead sulfide precipitate upon contact with lead acetate, blackening the paper (Lee and Simard, 1984). Cheeses manufactured with $L b$. nodensis resulted in distinct blackening of the paper, indicative of $\mathrm{H}_{2} \mathrm{~S}$; however, the paper remained unchanged in the presence of cheeses that did not contain the adjunct (Figure 3A). This result confirmed that Lb. nodensis CSK964 was responsible for the production of $\mathrm{H}_{2} \mathrm{~S}$ in Gouda cheese.

Table 5. Volatile sulfur compounds (arbitrary units $\times 1,000$ ) isolated from Gouda cheeses at 42 and $91 \mathrm{~d}$ of ripening ${ }^{1}$

\begin{tabular}{|c|c|c|c|c|}
\hline Volatile compound & $\begin{array}{l}\text { DVI only } \\
\text { (vat 1) }\end{array}$ & $\begin{array}{c}\text { DVI + CSK964 } \\
\quad(\text { vat } 2)\end{array}$ & $\begin{array}{c}\text { BSC } \\
\text { (vat 3) }\end{array}$ & $\begin{array}{c}\text { BSC + CSK964 } \\
(\text { vat } 4)\end{array}$ \\
\hline \multicolumn{5}{|l|}{ Methanethiol } \\
\hline d 42 & 3.1 & 23.38 & $0^{2}$ & 0 \\
\hline d 91 & 4.18 & 22.02 & 0 & 2.11 \\
\hline \multicolumn{5}{|l|}{ Hydrogen sulfide } \\
\hline d 42 & 0 & 0.46 & 0 & 4.56 \\
\hline d 91 & 0 & 0.67 & 0 & 17.12 \\
\hline \multicolumn{5}{|l|}{ Carbon disulfide } \\
\hline $\mathrm{d} 42$ & $5,706.25$ & $4,074.45$ & $2,949.17$ & $4,829.88$ \\
\hline d 91 & $7,090.3$ & $6,083.27$ & $6,407.33$ & $5,296.38$ \\
\hline \multicolumn{5}{|l|}{ Dimethyl disulfide } \\
\hline d 42 & 4.74 & 5.59 & 0 & 0 \\
\hline d 91 & 4.9 & 14.26 & 0 & 0 \\
\hline \multicolumn{5}{|l|}{ Dimethyl sulfide } \\
\hline d 42 & 496.78 & 428.84 & 213.3 & 353.61 \\
\hline d 91 & 925.38 & 539.1 & 930.38 & 494.98 \\
\hline \multicolumn{5}{|l|}{ Dimethyl trisulfide } \\
\hline d 42 & 0 & 0 & 0 & 0 \\
\hline d 91 & 0 & 0 & 0 & 0 \\
\hline \multicolumn{5}{|l|}{ Dimethyl sulfone } \\
\hline d 42 & 5.74 & 5 & 3.03 & 2.58 \\
\hline d 91 & 4.38 & 7.64 & 3.75 & 3 \\
\hline \multicolumn{5}{|l|}{ Dimethyl sulfoxide } \\
\hline d 42 & 0 & 0 & 0 & 0 \\
\hline d 91 & 0 & 0 & 0 & 0 \\
\hline \multicolumn{5}{|l|}{ Carbonyl sulfide } \\
\hline d 42 & 0 & 0.49 & 0 & 0 \\
\hline d 91 & 0 & 0 & 0 & 0.94 \\
\hline
\end{tabular}

${ }^{1}$ CSK964 = Lactobacillus nodensis CSK964 (adjunct culture); DVI = direct vat inoculum; BSC = bulk starter culture.

${ }^{2} 0=$ under detectable limit. 


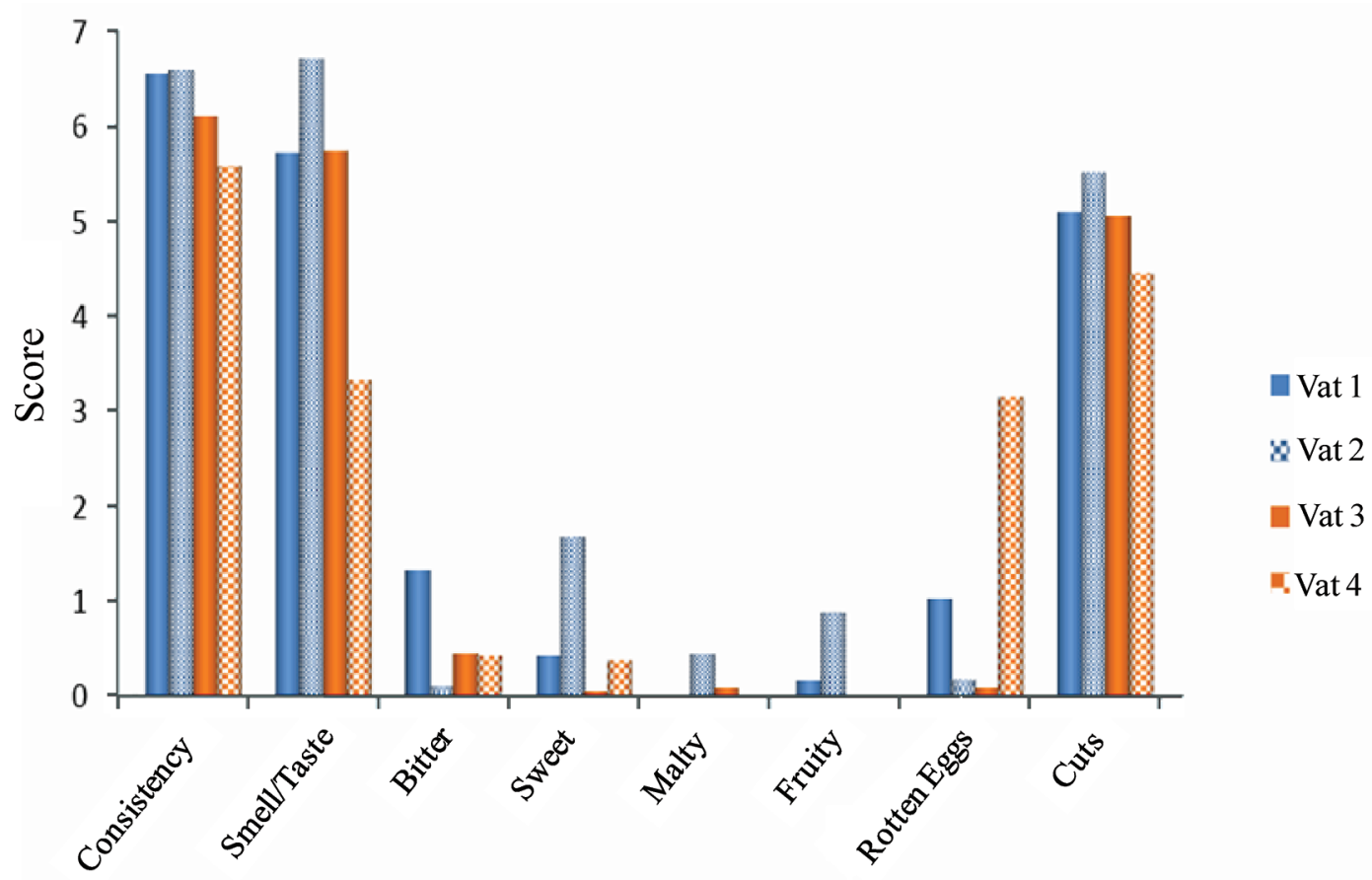

Sensory Attribute

Figure 2. Sensory and textural evaluation of Gouda cheeses following $42 \mathrm{~d}$ of ripening. Vat $1=$ direct vat inoculum; vat $2=$ direct vat inoculum + Lactobacillus nodensis CSK964; vat $3=$ bulk starter culture; vat $4=$ bulk starter culture + Lb. nodensis CSK964. Color version available online.

To determine whether the production of $\mathrm{H}_{2} \mathrm{~S}$ by $L b$. nodensis was strain-specific, we assessed 7 Lactobacillus strains using the above assay (Figure 3B). Of the 7 analyzed, Lb. nodensis, Lb. casei DPC6125, and $L b$. acidophilus DPC5378 showed superior growth in the MMSB compared with the other strains. However, the lead acetate paper showed considerable blackening only with $L b$. nodensis, indicating the production of $\mathrm{H}_{2} \mathrm{~S}$. In the presence of the other strains, the lead acetate paper remained unchanged except for a faint blacking of the paper edges.

The number of $L b$. nodensis cells required to produce sufficient $\mathrm{H}_{2} \mathrm{~S}$ in MMSB to blacken the lead acetate paper was confirmed to be $10^{7} \mathrm{cfu} / \mathrm{mL}$, because concentrations below $10^{7} \mathrm{cfu} / \mathrm{mL}$ caused no obvious color change (Figure $3 \mathrm{C}$ ).

\section{CONCLUSIONS}

We assessed the effectiveness of $L b$. nodensis CSK964 as a suitable adjunct for Gouda cheese. The presence of the adjunct under certain conditions resulted in greater concentrations of free amino acids, indicating its ability to enhance secondary proteolysis and significantly alter the flavor profile during ripening by increasing the presence of volatile sulfur compounds, including
$\mathrm{H}_{2} \mathrm{~S}$ and methanethiol. Combination with a BSC in the presence of the microbial rennet Milase resulted in a strong sulfur-flavored cheese, described as "unpleasant." However, combination with a DVI in the presence of Kalase resulted in a cheese with low scores for sulfur-associated flavors and which scored well in terms of smell and taste. Interestingly, the viability of the adjunct was compromised in the presence of the bacteriocin-producing DVI due to its sensitivity to nisin, which presumably had an effect on the abundance of volatile sulfur compounds. We verified the ability of $L b$. nodensis CSK964 to produce $\mathrm{H}_{2} \mathrm{~S}$ using lead acetate paper in the presence of MMSB, where a level of $10^{7} \mathrm{cfu} /$ $\mathrm{mL}$ was required. Previous analysis of the draft genome sequence of the strain confirmed the presence of genes for cysteine biosynthesis and catabolism, prerequisites for volatile sulfur compound production. Therefore, $L b$. nodensis CSK964 has potential as an adjunct culture for the production of industrial-scale Gouda cheese, with the ability to dramatically alter flavor formation during the ripening period.

\section{ACKNOWLEDGMENTS}

This project was funded by CSK Food Enrichment B.V. (Ede, the Netherlands). 
(A)

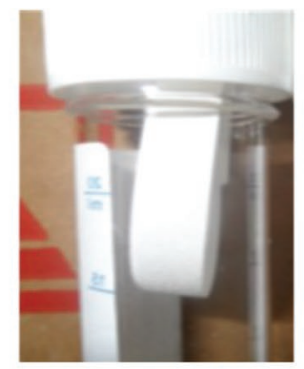

Lb. nodensis

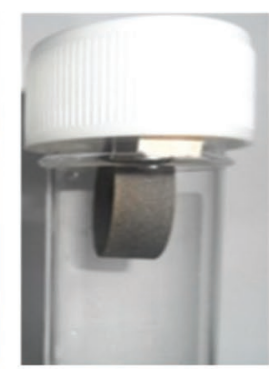

Lb. nodensis ${ }^{+}$

(B)
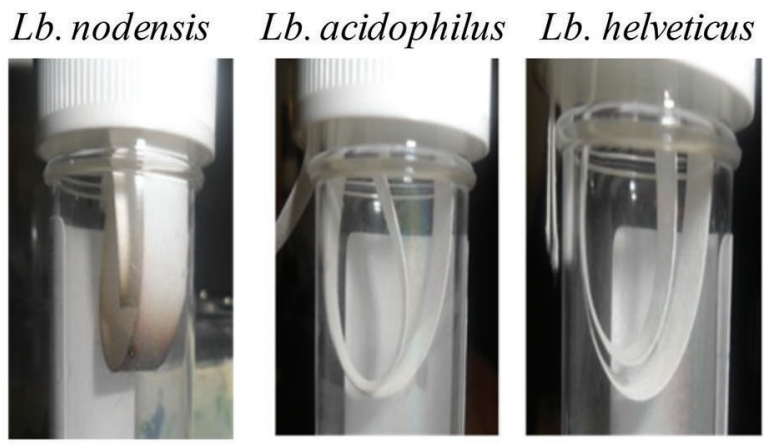

(C)
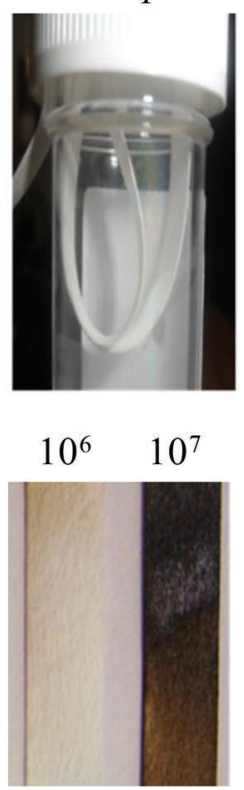

Figure 3. (A) Effect of Gouda cheese with $(+)$ and without $(-)$ Lactobacillus nodensis on lead acetate paper when suspended in modified motility sulfide broth. (B) Assessment of the $\mathrm{H}_{2} \mathrm{~S}$-producing capabilities of several Lactobacillus strains compared with Lb. nodensis using lead acetate paper as an indicator of $\mathrm{H}_{2} \mathrm{~S}$ production. (C) Determination of cell numbers of $L b$. nodensis required to generate $\mathrm{H}_{2} \mathrm{~S}$ using lead acetate paper. Color version available online.

\section{REFERENCES}

An, Z., X. He, W. Gao, W. Zhao, and W. Zhang. 2014. Characteristics of miniature Cheddar-type cheese made by microbial rennet from Bacillus amyloliquefaciens: A comparison with commercial calf rennet. J. Food Sci. 79:M214-M221.

Bansal, N., P. Piraino, and P. L. H. McSweeney. 2010. Determination of proteolysis in cheese. Pages 405-426 in Handbook of Dairy Foods Analysis. L. M. L. Nollet, and F. Toldra, ed. CRC Press, Boca Raton, FL.

Benech, R.-O., E. Kheadr, C. Lacroix, and I. Fliss. 2003. Impact of nisin producing culture and liposome-encapsulated nisin on ripening of Lactobacillus added-Cheddar cheese. J. Dairy Sci. 86:1895-1909.

Burbank, H., and M. C. Qian. 2008. Development of volatile sulphur compounds in heat-shocked and pasteurized milk cheese. Int. Dairy J. 18:811-818.

Chapot-Chartier, M.-P., C. Deniel, M. Rousseau, L. Vassal, and J. C. Gripon. 1994. Autolysis of two strains of Lactococcus lactis during cheese ripening. Int. Dairy J. 4:251-269.

De Man, J. C., M. Rogosa, and M. E. Sharpe. 1960. A medium for the cultivation of lactobacilli. J. Appl. Microbiol. 23:130-135.

de Ruyter, P., O. P. Kuipers, W. C. Meijer, and W. M. De Vos. 1997. Food-grade controlled lysis of Lactococcus lactis for accelerated cheese ripening. Nat. Biotechnol. 15:976-979.

Dobson, A., S. Mills, L. M. Serrano, C. Griffin, J. Brandsma, W. C. Meijer, R. P. Ross, and C. Hill. 2014. The genome of Lactobacillus nodensis reveals the basis for flavour production in this industrial adjunct. Abstract B054 in 11th Symposium on Lactic Acid Bacteria, Egmond aan Zee, the Netherlands. Biomed Central, London, UK.

Fox, P. 1963. Potentiometric determination of salt in cheese. J. Dairy Sci. 46:744-745.

Garcia, V., S. Rovia, R. Teruel, K. Boutoial, J. Rodríguez, I. Roa, and M. B. López. 2012. Effect of vegetable coagulant, microbial coagulant and calf rennet on physiochemical, proteolysis, sensory and texture profiles of fresh goats cheese. Dairy Sci. Technol. 92:691-707.

Gobbetti, M., M. De Angelis, R. Di Cagno, L. Mancini, and P. F. Fox. 2015. Pros and cons for using non-starter lactic acid bacteria (NSLAB) as secondary/adjunct starters for cheese ripening. Trends Food Sci. Technol. 45:167-178.

Hannon, J., M. Wilkinson, C. Delahunty, J. Wallace, P. Morrissey, and T. Beresford. 2003. Use of autolytic starter systems to accelerate the ripening of Cheddar cheese. Int. Dairy J. 13:313-323.

Hirel, P. H., M. Schmitter, P. Dessen, G. Fayat, and S. Blanquet. 1989. Extent of N-terminal methionine excision from Escherichia coli proteins is governed by the side-chain length of the penultimate amino acid. Proc. Natl. Acad. Sci. USA 86:8247-8251.

IDF. 1982. Cheese and processed cheese - determination of total solids content. International Dairy Federation Standard: No 4. IDF, Brussels, Belgium.

IDF. 1986. Determination of nitrogen content (Kjeldahl Method) and calculation of crude protein content. International Dairy Federation Standard: No 20A. IDF, Brussels, Belgium.

Jacob, M., D. Jaros, and H. Rohm. 2010. The effect of coagulant type on yield and sensory properties of semihard cheese from laboratory-, pilot- and commercial-scale productions. Int. J. Dairy Technol. $63: 370-380$

Jacob, M., D. Jaros, and H. Rohm. 2011. Recent advances in milk clotting enzymes. Int. J. Dairy Technol. 64:14-33.

Kashiwagi, T., T. Suzuki, and T. Kamakura. 2009. Lactobacillus nodensis sp. nov., isolated from rice bran. Int. J. Syst. Evol. Microbiol. 59:83-86.

Kuchroo, C., and P. Fox. 1982. Soluble nitrogen in Cheddar cheese: Comparison of extraction procedures. Milchwissenschaft 37:331335.

Landaud, S., S. Helinck, and P. Bonnarme. 2008. Formation of volatile sulfur compounds and metabolism of methionine and other sulfur compounds in fermented food. Appl. Microbiol. Biotechnol. 77:1191-1205.

Lee, B., and R. Simard. 1984. Evaluation of methods for detecting the production of $\mathrm{H}_{2} \mathrm{~S}$, volatile sulfides, and greening by lactobacilli. J. Food Sci. 49:981-983.

Lee, W.-J., D. S. Banavara, J. E. Hughes, J. K. Christiansen, J. L. Steele, J. R. Broadbent, and S. A. Rankin. 2007. Role of cystathionine $\beta$-lyase in catabolism of amino acids to sulfur volatiles by genetic variants of Lactobacillus helveticus CNRZ 32. Appl. Environ. Microbiol. 73:3034-3039.

Liu, M., A. Nauta, C. Francke, and R. J. Siezen. 2008. Comparative genomics of enzymes in flavor-forming pathways from amino acids in lactic acid bacteria. Appl. Environ. Microbiol. 74:4590-4600.

Marilley, L., and M. Casey. 2004. Flavours of cheese products: Metabolic pathways, analytical tools and identification of producing strains. Int. J. Food Microbiol. 90:139-159.

Martín-Platero, A. M., E. Valdivia, M. Maqueda, I. Martín-Sánchez, and M. Martínez-Bueno. 2008. Polyphasic approach to bacterial dynamics during the ripening of Spanish farmhouse cheese, using culture-dependent and-independent methods. Appl. Environ. Microbiol. 74:5662-5673. 
Masoud, W., M. Takamiya, F. K. Vogensen, S. Lillevang, W. A. AlSoud, S. J. Sørenson, and M. Jakobsen. 2011. Characterization of bacterial populations in Danish raw milk cheeses made with different starter cultures by denaturating gradient gel electrophoresis and pyrosequencing. Int. Dairy J. 21:142-148.

McSweeney, P. L. 2004. Biochemistry of cheese ripening. Int. J. Dairy Technol. 57:127-144.

Mehmet, C., and S. Bedia. 2015. Effects of different coagulent enzymes used on quality of traditional Orgu cheese (braided cheese). Mljekarstvo 65:57-65.

Mills, S., L. M. Serrano, C. Griffin, P. M. O'Connor, G. Schaad, C. Bruining, C. Hill, R. P. Ross, and W. C. Meijer. 2011. Inhibitory activity of Lactobacillus plantarum LMG P-26358 against Listeria innocua when used as an adjunct starter in the manufacture of cheese. Microb. Cell Fact. 10(Suppl. 1):S7.

Reiter, B., Y. Sorokin, A. Pickering, and A. J. Hall. 1969. Hydrolysis of fat and protein in small cheeses made under aseptic conditions. J. Dairy Res. 36:65-76.

Sallami, L., E. Kheadr, I. Fliss, and J. Vuillemard. 2004. Impact of autolytic, proteolytic, and nisin-producing adjunct cultures on biochemical and textural properties of Cheddar cheese. J. Dairy Sci. $87: 1585-1594$.

Savijoki, K., H. Ingmer, and P. Varmanen. 2006. Proteolytic systems of lactic acid bacteria. Appl. Microbiol. Biotechnol. 71:394-406.

Settanni, L., and G. Moschetti. 2010. Non-starter lactic acid bacteria used to improve cheese quality and provide health benefits. Food Microbiol. 27:691-697.

Sheehan, J. J. 2007. Syneresis. Pages 77-78 in Cheese Problems Solved. P. L. H. McSweeney, ed. Wood Head Publishing Ltd., Cambridge, UK

Singh, T., M. Drake, and K. Cadwallader. 2003. Flavor of Cheddar cheese: A chemical and sensory perspective. Compr. Rev. Food Sci. Food Saf. 2:166-189.
Smit, G., B. A. Smit, and W. J. M. Engels. 2005. Flavour formation by lactic acid bacteria and biochemical flavour profiling of cheese products. FEMS Microbiol. Rev. 29:591-610.

Stadhouders, J., and G. Hup. 1975. Factors affecting bitter flavour in Gouda cheese. Neth. Milk Dairy J. 29:335-353.

Ufuk, E.-V., and O. Tulay. 2012. Determination of free amino acids in whole-fat Turkish white brined cheese produced by animal and microbial milk-clotting enzymes with and without addition of starter culture. 2012. Mljekarstvo 62:241-250.

van den Berg, G., W. C. Meijer, E.-M. Düsterhöft, and G. Smit. 2004 Gouda and related cheeses. Pages 103-140 in Cheese: Chemistry, Physics and Microbiology. Vol. 2. 3rd ed. P. F. Fox, P. L. H. McSweeney, T. M. Cogan, and T. P. Guinee, ed. Elsevier Academic Press, London, UK.

van Kranenburg, R., M. Kleerebezem, J. van Hylckama Vlieg, B. M. Ursing, J. Boekhorst, B. A. Smit, E. H. Ayad, G. Smit, and R. J. Siezen. 2002. Flavour formation from amino acids by lactic acid bacteria: Predictions from genome sequence analysis. Int. Dairy J. 12:111-121.

Wang, H., L. Cui, W. E. I. Chen, and H. Zhang. 2011. An application in Gouda cheese manufacture for a strain of Lactobacillus helveticus ND01. Int. J. Dairy Technol. 64:386-393.

Welthagen, J. J., and B. C. Viljoen. 1998. Yeast profile in Gouda cheese during processing and ripening. Int. J. Food Microbiol 41:185-194.

Wilkinson, M. G., T. P. Guinee, and P. F. Fox. 1994a. Factors which may influence the determination of autolysis of starter bacteria during Cheddar cheese ripening. Int. Dairy J. 4:141-160.

Wilkinson, M. G., T. P. Guinee, D. M. O'Callaghan, and P. F. Fox. 1994b. Autolysis and proteolysis in different strains of starter bacteria during Cheddar cheese ripening. J. Dairy Res. 61:249-262. 